\title{
An Evidence-based Framework for Reporting Student Nurse Medication Incidents: Errors, Near Misses and Discovered Errors
}

\author{
Michelle A. Freeman \\ University of Windsor, mfreeman@uwindsor.ca \\ Susan Dennison \\ University of Windsor, dennison@uwindsor.ca \\ Natalie Giannotti \\ University of Windsor, natalieg@uwindsor.ca \\ Mary J. Voutt-Goos \\ University of Windsor, vouttg@uwindsor.ca
}

Follow this and additional works at: https://qane-afi.casn.ca/journal

Part of the Nursing Commons

\section{Recommended Citation}

Freeman, Michelle A.; Dennison, Susan; Giannotti, Natalie; and Voutt-Goos, Mary J. (2020) "An Evidence-based Framework for Reporting Student Nurse Medication Incidents: Errors, Near Misses and Discovered Errors," Quality Advancement in Nursing Education - Avancées en formation infirmière: Vol. 6: Iss. 3, Article 4.

DOI: https://doi.org/10.17483/2368-6669.1233

This Article is brought to you for free and open access by Quality Advancement in Nursing Education - Avancées en formation infirmière. It has been accepted for inclusion in Quality Advancement in Nursing Education - Avancées en formation infirmière by an authorized editor of Quality Advancement in Nursing Education - Avancées en formation infirmière. 
Developing nursing students' competencies in medication administration is a major focus in undergraduate nursing programs. Competent practice, guided by constructivist learning theory, requires active learning by the student that includes the application of knowledge of pharmacology and administration techniques, the following of safe practices, policies, and procedures, and critical reasoning and decision making (Bourbonnais \& Caswell, 2014; Brame, 2016). While teaching and learning begin in the classroom and laboratory, the clinical environment is recognized as a more real-life experience where students and instructors are faced with an array of complex factors that influence the correct outcome (i.e., the right medication, to the right patient, at the right time, for the right reason). Influencing factors include distractions, workload, team communication, and organizational structures and policies (Bourbonnais \& Caswell, 2014). These factors contribute to the high incidence of medication errors, a leading cause of global harm (World Health Organization, 2017). Preventable errors occurring during the medication management process in hospitals are associated with additional length of stay and health care costs (Risk Analytica, 2017). Globally, medication administration errors occur in as many as $19.6 \%$ of medication doses (Keers et al., 2013). A Canadian retrospective hospital study found approximately a quarter of preventable adverse events were related to medication and fluid errors (Baker et al., 2004). The reduction of errors therefore is a major focus in health care and in nursing education.

The actual incidence of medication errors, however, is unknown because of underreporting. Underreporting has been identified as resulting from confusion over the definition of a reportable medication error, onerous reporting processes, and fear of the consequences in cultures perceived as punitive (Covell \& Ritchie, 2009; Hewitt, 2010). Nurses in a Canadian study believed that more than $40 \%$ of errors that occurred on their unit were not reported (Covell \& Ritchie, 2009). In their seminal study, Leape and colleagues (1995) found that although $38 \%$ of errors were made by nurses at the administration stage, they were the professional most likely to intercept errors made during the prescribing, transcription, and dispensing stages. The lack of reporting fails to capture this important safety role that nurses play during the administration phase.

Nurse educators and nursing students play a key role in both reducing medication error incidence and reporting errors. Published studies on medication errors by nursing students, although limited in number, indicate that errors occur during clinical placements. One challenge in applying these studies' findings in nursing education is the lack of consensus on how the factors that contributed to the errors are organized, reported, and analyzed. Wolf and colleagues (2006) identified that there was limited research on the attributes of student-made medication errors and effective teaching strategies to help students avoid them. They conducted a retrospective study on medication errors by students $(N=1305)$ filed by US hospitals in the MEDMARX database over five years. Errors in this database were attributed to nursing students if they were made during the administration phase. The structured error reports were completed by hospital staff and included multi-select pick lists with 13 medication error types, 63 causes of errors, and 18 items on contributing factors. Harding and Petrick (2008) conducted a retrospective review of 77 medication errors over three years by nursing students in a Canadian four-year baccalaureate program. Data were categorized as errors of commission (medication given incorrectly and violating one of the rights of medication administration) and errors of omission (medications not given). Dolansky and colleagues (2013) used a root cause analysis to analyze a case study of an error made by an undergraduate nursing student. They identified multiple contributing factors and sub-factors organized as environmental, personal, unit communication and culture, and education. Cooper (2014) analyzed nursing student medication errors at a US university nursing school by 
categorizing the errors into administration rights, system issues, and knowledge and understanding. The Pennsylvania Patient Safety Authority (Hess et al., 2016) analyzed five years of medication errors and student detected errors by health care students (nurses, pharmacists, and medical students) from their Pennsylvania Patient Safety Reporting System. Their analysis was organized by errors reaching the patient and those detected by students before they reached the patient. Errors were categorized by phase of medication administration. The Institute for Safe Medication Practices Canada (ISMP Canada, 2018) analyzed student-associated medication incidents from voluntary reports submitted to three ISMP Canada medication incident reporting databases between 2013 and 2017. Incidents were analyzed using the methodology for multiincident analysis outlined in the Canadian Incident Analysis Framework (Incident Analysis Collaborating Parties, 2012). Errors identified by students accounted for approximately $40 \%$ of the analyzed reports. Findings, analyzed qualitatively, were summarized under broad themes related to a culture of safety enablers or challenges (e.g., preceptor-associated challenges).

As this brief summary illustrates, comparing medication errors, the associated system factors, and the interconnectedness of these factors is challenging because of the variety of terminology and analysis methods used. These also limit the understanding of the full scope of the problem, including the factors that are impacting safe medication administration and their subsequent application to education and clinical practice (Harding \& Petrick, 2008; Rohde \& Domm, 2018). A systematic review of medication errors involving nursing students was recently conducted by Asensi-Vicente and colleagues (2018). They analyzed 19 studies published between 2005 and 2017. Their findings support high rates of errors by nursing students, under reporting of these errors, and differences in the way findings are reported; they caution that the studies that they included varied in content, design, and methodology and were not assessed for quality.

The purpose of this article is to describe a quality improvement project to test a redesigned section in our online medication incident reporting system for a school of nursing. This section incorporates a framework to support the identification and categorization of a broad array of factors described in the literature as contributing to medication incidents. The goal was to improve the clarity of reporting to allow the tracking of the contributing factors for different types of incidents, improve our understanding of these incidents, and enable the development of targeted education strategies to reduce and/or prevent future incidents. This project took place in a four-year university nursing program in southwestern Ontario with approximately 800 undergraduate students. The specific aims were to

- develop and define evidence-based factors adapted for reporting in a nursing school context that contribute to medication incidents

- test the framework by tracking and analyzing the frequency of incidences (medication errors, near misses, discovered errors) and their contributing factors over one school year

This quality improvement project follows the Standards for Quality Improvement Reporting Excellence 2.0 (SQUIRE 2.0) guidelines (Ogrinc et al., 2015).

The creation of a culture of safety was viewed as crucial to achieving the aims of this project because of its influence on how errors are managed, reported, and shared (Agency for Healthcare Research and Quality, 2019). Reason's (1997) culture of safety theoretical framework, encompassing four elements, guided this project. The elements are a reporting culture (i.e., where reporting is encouraged and acknowledged), a flexible culture (i.e., where power gradients/hierarchies are reduced and students are encouraged to report), a just culture (i.e., where 
individuals are treated justly/fairly when errors occur), and a learning culture (i.e., where the school and its placement agencies learn from incidents and implement changes to reduce them). The complex scope of the project, the process steps, and the outcomes are illustrated in Figure 1 and explained in the following section.

\section{Figure 1}

Process Steps in Redesign of a Medication Incident Reporting System Using Reason's (1997) Culture of Safety Framework

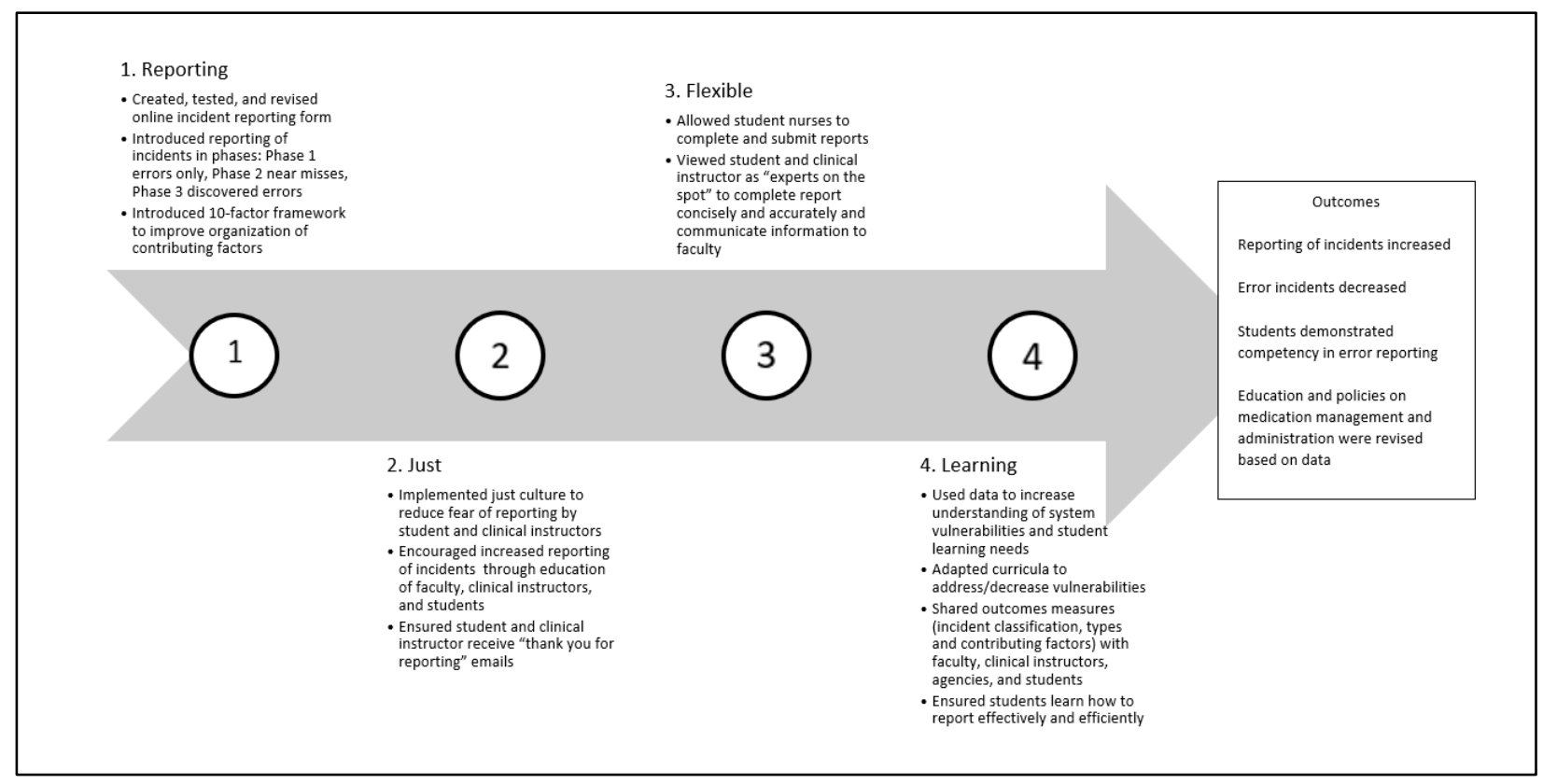

\section{Method}

The reporting of medication errors is a priority in nursing schools. Reporting of errors and near misses is an entry to practice expectation related to professional responsibility and accountability of the College of Nurses of Ontario (CNO, 2018). Historically, our nursing school used a paper-based reporting system for medication errors. As with other paper-based reporting systems, it proved to be inefficient for tracking and trending errors. Approximately 10 years ago, an online system was implemented for reporting medication errors. Its design was based on a traditional hospital-based reporting format, which included a broad list of contributing factors that were not categorized and proved difficult to analyze into actionable findings. In 2014, the reporting of near miss medication incidents was added. The online form was again redesigned in 2017 with the addition of discovered errors (i.e., errors made by other members of the team but discovered by a student). This addition was deemed necessary to distinguish between errors by our students and those that they found as they prepared to administer medications and reviewed the patient's medication orders and record. Simple definitions were purposely chosen to encourage reporting; feedback was provided if an incident was categorized inappropriately.

After a review of the literature on the causes of medication errors and reporting systems, the 10 system elements identified by the ISMP (Cohen, 2007) were adapted as a structure to design our reporting format to better categorize, organize, and analyze the wide array of contributing 
factors. The ISMP, in collaboration with other groups such as USP-ISMP Medication Error Reporting System and the Food and Drug Administration MedWatch program, reviewed thousands of medication error reports and visited hundreds of sites after incidents occurred (Cohen, 2007). They found that the causes of errors were "multifactorial, cutting across many processes, lines of responsibility and organization wide systems" (p. 55) but resulted from similar circumstances. From this analysis, they identified the 10 system elements that influence medication management with errors directly related to weaknesses or failures in these system elements (Cohen, 2007, p. 56).

For application in our online incident reporting form, the system elements were adapted to better reflect the roles and responsibilities of nurses and nursing schools in the medication administration process. Definitions of the factors and examples are illustrated in Table 1. For example, "medication delivery device acquisition, use, and monitoring" was reworded to state "drug delivery device" since nursing schools do not play a role in device acquisition in their clinical placement sites. "Drug standardization, storage, and distribution" was reworded to "drug storage and availability." "Environment" was revised to "environment and human limitations" (e.g., fatigue) since both have been identified as contributing to errors by nurses. "Patient education" was revised to include the family and the concept of engagement (Carman et al., 2013) to better reflect the broader role that nurses assume with patients and families. "Quality process and risk management" was revised to "policies and procedures," language more commonly used in nursing practice.

\section{Table 1}

10-Factor Framework for Reporting Contributing Factors in Medication Incidents

\begin{tabular}{|l|l|}
\hline \multicolumn{1}{|c|}{ Factors } & \multicolumn{1}{c|}{ Definition with examples } \\
\hline Patient & \multicolumn{1}{c|}{$\begin{array}{l}\text { Information on the individual patient includes unique identifiers, demographics, } \\
\text { and clinical information/data that are considered when prescribing, transcribing, } \\
\text { dispensing, administering, and documenting. } \\
\text { Examples: full name, date of birth, age, medical history, diagnosis, allergies, } \\
\text { weight, vital signs, lab results, pregnancy status }\end{array}$} \\
\hline Drug information & $\begin{array}{l}\text { Information on each drug is known or accessed when prescribing, transcribing, } \\
\text { dispensing, and administering medications. } \\
\text { Examples: recommended dosages, precautions, contraindications, drug/drug or } \\
\text { drug/food interactions, side effects, current drug information accessible, protocols } \\
\text { or order sets }\end{array}$ \\
\hline Communication & $\begin{array}{l}\text { Communication includes all forms of verbal and written communication among } \\
\text { the health care team during all stages of the medication management process. } \\
\text { Examples: prescribing orders, transcribed orders, and medication administration } \\
\text { record (MAR) that are legible/clear/complete }\end{array}$ \\
\hline $\begin{array}{l}\text { Drug names, } \\
\text { labelling, and } \\
\text { packaging }\end{array}$ & $\begin{array}{l}\text { Drug names, labels, and packaging are clear/complete/legible. Packaged drugs are } \\
\text { intact with no signs of deterioration. } \\
\text { Examples: clearly identified drug name and dose on all medication containers; } \\
\text { look-alike or sound-alike drugs packaged and labelled clearly to avoid confusion } \\
\text { (e.g., tall man lettering) }\end{array}$ \\
\hline $\begin{array}{l}\text { Drug storage and } \\
\text { availability }\end{array}$ & $\begin{array}{l}\text { Drugs are distributed and available for on-time administration. Unit stocked drugs } \\
\text { are available and stored to support timely and safe preparation. } \\
\text { Examples: drugs prepared in unit-dose; limited drug concentrations available; IV } \\
\text { drugs prepared in pharmacy }\end{array}$ \\
\hline
\end{tabular}




\begin{tabular}{|l|l|}
\hline $\begin{array}{l}\text { Drug delivery } \\
\text { device }\end{array}$ & $\begin{array}{l}\text { Devices are prepared/programmed correctly and assessed/monitored for correct } \\
\text { delivery of drugs. } \\
\text { Examples: infusion pumps, implantable pumps and devices, infusion lines, } \\
\text { syringes (oral and parenteral); procedures for reporting/removing malfunctioning } \\
\text { devices }\end{array}$ \\
\hline $\begin{array}{l}\text { Environmental } \\
\text { and human } \\
\text { limitations }\end{array}$ & $\begin{array}{l}\text { Stressors in the work environment and the limitations of humans influence on the } \\
\text { safety and efficiency of the medication administration process. } \\
\text { Examples: lighting, noise, interruptions, distractions, fatigue, workload/task } \\
\text { overload }\end{array}$ \\
\hline $\begin{array}{l}\text { Competency and } \\
\text { education }\end{array}$ & $\begin{array}{l}\text { Knowledge, skill, and/or abilities of all members of the health care team } \\
\text { contribute to safe medication management. Continuing education is required to be } \\
\text { competent in new medications and practices. } \\
\text { Examples: drug knowledge, experience in administering the drug, knowledge of } \\
\text { protocols, knowledge of required patient assessment and monitoring, knowledge } \\
\text { of safe practices }\end{array}$ \\
\hline $\begin{array}{l}\text { Patient/family } \\
\text { education and } \\
\text { engagement }\end{array}$ & $\begin{array}{l}\text { Patient/family are actively involved in all stages of the medication administration } \\
\text { process including education. } \\
\text { Examples: patient preferences considered; patient informed of the medication(s) } \\
\text { they are receiving and are encouraged to ask questions about their medications } \\
\text { before drugs are administered; education is designed to address language } \\
\text { barriers/needs and health literacy }\end{array}$ \\
\hline $\begin{array}{l}\text { Policies and } \\
\text { procedures }\end{array}$ & $\begin{array}{l}\text { Processes are designed to reduce the opportunity for drug errors or detect them } \\
\text { before they reach the patient. } \\
\text { Examples: use of 3 drug label checks; patient identification using 2 patient } \\
\text { identifiers; independent double checks for high alert drugs; student nurses } \\
\text { observed during all phases of medication administration }\end{array}$ \\
\hline
\end{tabular}

Note. The framework for incident reporting in nursing schools was adapted from the 10 system elements described by Cohen (2007): patient information; drug information; communication; drug labelling, packaging, and nomenclature; drug standardization, storage, and distribution; medication delivery device acquisition, use, and monitoring; environmental factors; staff competency and education; patient education; and quality process and risk management.

The online form is completed by the nursing student either independently or in collaboration with the clinical instructor. The classification of the incident is identified, and a full description of the medication incident is entered. This is followed by 10 questions, each asking whether the factor (yes or no) contributed to the incident. If yes, the student selects from a list of specific issues that might have played a role in the event. The prompts serve two purposes; first, they introduce the student to issues that might not have been considered; second, they educate the student on all the system factors that contribute to an incident. It takes less than five minutes to complete the report. When reporting discovered errors, students are informed that they are not required to complete this part of the form since they were not involved in the incident. The majority complete it. This exercise offers them an opportunity to reflect on the factors that likely contributed to the event (e.g., medication discovered at bedside indicating violation of policies and procedures) and serves as another safety lesson on how easily errors can happen and the nurse's role in preventing them.

In addition to reporting in the nursing school's system, errors are reported per policy in the agency system and guided by the clinical instructor. Near misses are reported in the agency system if appropriate. For example, a student error in preparing the correct dose indicates a knowledge deficit and learning opportunity and is not reported in the agency's system. Discovered errors are reported to the patient's nurse, who guides the reporting and actions taken based on the type of 
error. Reports are reviewed for accuracy and completeness by the nursing school's clinical leads in 48 to 72 hours and shared with the leadership team. Students and the clinical instructor receive a letter acknowledging their report and thanking them for contributing to a culture of safety.

The outcome measures for this project included the number of reports of medication incidents by classification (errors, near misses, and discovered errors), the type of error by classification (e.g., wrong time) and the factors that contributed to the errors and near miss incidents.

\section{Ethical Considerations}

This project was approved by the Research Ethics Boards (REBs) as a quality assurance/ quality improvement project at the home university of the researchers. The online reporting form is part of our school's quality assurance/quality improvement program. All reported data are deidentified (student, instructor, and placement site removed). The findings are communicated to our safety committees, faculty council, placement agencies, students, and clinical instructors in meetings and integrated in ongoing education (e.g., Institute for Health Improvement Open School educational offerings). Information on all the incidents inform schools of nursing and placement agencies of the vulnerabilities in the system. The goal is to improve individual performance and advocate for improvements in systems where our students practice, thereby reducing opportunities for errors.

\section{Results}

Before data analysis, the data were explored for accuracy of entries and missing data. Although our students have clinical experiences in community settings, most reports were submitted during hospital placements. A total of 88 medication incidents were reported between September 2017 and June 2018. The majority were near misses (61\%) followed by discovered errors $(22 \%)$ and errors $(17 \%)$. Respondents were asked to classify the error involved (see Table $2)$. Based on totals, one third of all incidents were an incorrect dose/quantity of medication $(n=$ $29 ; 33 \%)$; almost one fifth $(n=16 ; 18 \%)$ were a missed dose, followed by $14 \%(n=12)$ involving wrong medication and $10 \%(n=9)$ an extra medication dose. The remaining categories, all $8 \%$ or less, included wrong time, wrong patient, prescribing error, expired product, and wrong administration. Incident type, by classification, shared similarities and differences. For example, incorrect dose was the most reported type for all classifications but errors were more frequently related to dose (incorrect, omission, extra), wrong medication or wrong time. Reports identified that none of the incidents resulted in patient harm.

\section{Table 2}

Incident Classification and Type of Error in Descending Order of Frequency

\begin{tabular}{lcccc}
\hline Incident type & \multicolumn{4}{c}{ Incident classification, $n(\%)$} \\
& $\begin{array}{c}\text { Errors, } 15 \\
(17)\end{array}$ & $\begin{array}{c}\text { Near miss, 54 } \\
(61)\end{array}$ & $\begin{array}{c}\text { Discovered, } 19 \\
(22)\end{array}$ & $\begin{array}{c}\text { Total, 88 } \\
(100)\end{array}$ \\
\hline & & & & \\
Incorrect dose & $4(27)$ & $20(37)$ & $5(26)$ & $29(33)$ \\
Missed dose & $4(27)$ & $8(15)$ & $2(11)$ & $16(18)$ \\
Wrong medication & $2(13)$ & $8(15)$ & $2(11)$ & $12(14)$ \\
Extra dose & $2(13)$ & $5(9)$ & $2(11)$ & $9(10)$ \\
Wrong time & $3(20)$ & $2(4)$ & $2(11)$ & $7(8)$ \\
Wrong patient & $0(0)$ & $3(6)$ & $1(5)$ & $4(5)$
\end{tabular}




$\begin{array}{lllll}\text { Prescribing error } & 0(0) & 3(6) & 0(0) & 3(3) \\ \text { Expired } & 0(0) & 3(6) & 0(0) & 3(3) \\ \text { Wrong route } & 0(0) & 1(2) & 1(5) & 2(2) \\ \text { Wrong administration } & 0(0) & 1(2) & 1(5) & 2(2)\end{array}$

technique

Note. All percentages are rounded to whole numbers.

Respondents were asked if a factor contributed to the error or near miss incidents and to indicate all that applied. Discovered errors are not included in this analysis as previously explained. Contributing factors varied by incident classification (see Table 3). Problems with environment/human limitations, communication, and the following of policies/procedures were a contributing factor in approximately two thirds of all errors; problems with competency/education were involved in $40 \%$. A lack of patient/family education and engagement contributed to one third (27\%). Issues with drug storage and availability and drug delivery devices were identified in $13 \%$. Of interest, drug information and drug names, labeling and packages did not contribute to these 15 error incidents.

Contributing factors in near miss incidents presented a different picture. All 10 contributing factors were involved in the 54 incidents. Communication problems were involved in half; environment/human limitations, competency/education, policies, and procedures were issues in one third; drug storage and availability were involved in eight incidents (15\%); information on the patient and drugs were a problem in approximately $10 \%$; and drug names, labelling, packaging; drug delivery device; and patient/family education were involved in less than $10 \%$.

\section{Table 3}

Contributing Factors in Errors and Near Miss Incidents

\begin{tabular}{lcc}
\hline Factors & \multicolumn{2}{c}{ Incident classification, $n(\%)$} \\
\hline & Errors, 15 & Near miss, 54 \\
& $n(\%)$ & $n(\%)$ \\
\hline Pt information & $2(13)$ & $6(11)$ \\
Drug information & $0(0)$ & $5(9)$ \\
Communication & $9(60)$ & $27(50)$ \\
Drugs names, labelling, packaging & $0(0)$ & $4(7)$ \\
Drug storage \& availability & $2(13)$ & $8(15)$ \\
Drug delivery device & $2(13)$ & $2(4)$ \\
Environment/human limitations & $10(67)$ & $15(28)$ \\
Competency \& education & $6(40)$ & $16(30)$ \\
Pt/fam education \& engagement & $4(27)$ & $2(4)$ \\
Policies \& procedures & $9(60)$ & $17(32)$ \\
\hline
\end{tabular}

Note. All percentages are rounded to whole numbers

\section{Discussion}

Researchers have approached the collection and analysis of medication incident data in a variety of ways and have acknowledged the limitations of these approaches. A lack of standardization of the many potential contributing factors results in data that do not tell the whole 
story and limits our understanding of the causes of these incidents and how to prevent them from happening again. Our 10-factor framework that organizes the contributing factors has demonstrated promise in improving this process. The framework includes a wide array of system factors that are supported by the literature as contributing to errors but not usually captured in incident reporting. For example, it reinforces the importance of patient involvement in a safe administration process, something that was absent from other reporting systems but recognized as key to safe medication management (Zhu et al., 2011). Harding and Petrick (2008) recognized the interconnectedness of the contributing factors and recommended the inclusion of more system factors that influence safe medication administration. Our framework addresses this concern by providing the opportunity for the student and clinical instructor to reflect on all the system factors that may have contributed to the incident (e.g., communication; patient/family engagement and education). A root cause analysis approach (Dolansky et al., 2013) to incident analysis is still recommended as an effective learning strategy. The 10-factor framework provides a structured, standardized approach that could guide a root cause analysis and ensure reflection on all potential contributors to a medication incident.

There are wide variations in what medication incidents are reported in nursing schools. Most reporting is focused on medication errors (Cooper, 2014; Dolansky et al., 2013; Harding \& Petrick, 2008) or medication errors and near miss incidents (Hess et al., 2016). Our school has evolved from reporting only errors to include near misses and discovered errors. The information we have learned has reinforced their importance, and each of these inform our medication management processes and curricula in different ways. We encourage students to report near misses. This allows them to reflect on their knowledge of the process. In addition, it teaches them how to complete a report. We reinforce that near-miss reports are "free lessons" (Reason, 2000) and provide an opportunity to prevent future incidents by revealing any underlying individual and system issues that can be addressed. The contributing factors to these incidents indicated that some of the near misses were the result of a lack of knowledge and experience (e.g., an incorrect dose of medication is prepared), thus allowing the student to reflect on and correct this deficit before a patient is harmed. For example, one actual near miss incident was the result of a confusing medication administration record, confusing medication orders, and distractions and workload; this error was caught when an independent double check was done, thus reinforcing the importance of safe practices.

No published studies were located on the reporting of discovered errors in nursing programs. Reporting discovered errors (e.g., a missed order from a previous shift; an intravenous antibiotic that was clamped) are important because they provide examples to students of proactive interventions to reduce patient harm and real-life lessons of the vulnerabilities that impact even experienced nurses. In addition, they inform the placement agencies in which nursing students play an important role in contributing to the safety of their patients. They also offer another method of identifying weaknesses in the medication process. Most importantly, these reports provide evidence that during the medication administration phase, nurses play an important quality and safety role by catching and correcting errors in the medication management process before they can reach the patient.

Retrospective reviews of medication incident reports (Cooper, 2014), often conducted at year-end proved useful in contributing to our understanding of student medication errors. Based on our experiences, however, this late review posed challenges because the information on reports was not always complete. Students might not include all the details relevant to the incident and 
might not identify all contributing factors. Our process includes the analysis of reports for accuracy and completeness within a few days of the submission, allowing for follow-up and a request for clarification and additional information. This feedback teaches students and their clinical instructors how to report more effectively and provides more accurate data for analysis.

As indicated in our analysis, contributing factors for errors and near misses varied. This finding is an important revelation, one that we have not seen in the literature. These data can guide nursing faculties in incident-specific interventions. For example, the data indicate that an incorrect dose was a problem in both errors and near misses. This information will be shared with theory, laboratory, and clinical teachers who can adapt their education and practice to address this problem. In our goal to reduce student nurse errors, the major contributing factors were environment/human limitations, communication, and people not following policies and procedures. We can focus on and reinforce these safe practices in our messaging to students and instructors. This information is valued by faculty and clinical instructors because it supports what they know to be true in practice. It also reinforces the contribution they make to improve safety through reporting.

The ground-breaking work of the Quality and Safety Education for Nursing faculty and board members (Cronenwett et al., 2007) emphasized the importance of preparing nurses for an increasingly complex health system by imbedding new competencies (patient-centred care, teamwork and collaboration, evidence-based practice, quality improvement, safety and informatics) in nursing curricula. They identified error and near miss reporting as a key skill to master. Our reporting format supports the acquisition of this skill and the other competencies. For example, patient-centred care is emphasized when the student is asked if a lack of patient/family involvement contributed to the incident. We have found that this is often an afterthought for the student who is focused on the skill acquisition of administering medications rather than on the patient.

This paper reports on one element of our incident reporting project. As previously discussed, Reason's (1997) culture of a safety framework has guided its planning and implementation over many years. Fear of reporting by nursing students and clinical instructors has been reduced by the implementation of a just culture; incident data are used to guide changes in curricula thereby supporting a learning culture; a flexible culture is implemented by allowing our nursing students an active role in the reporting process; and a reporting culture is encouraged by thanking students and clinical instructors for reporting and acknowledging clinical instructors who have increased their near miss reporting rates in their clinical groups with a patient safety leadership award.

The 10-factor framework offers an evidence-based approach for reporting and analyzing medication incident reports in nursing schools. It provides a nursing lens and gives nursing a voice by quantifying the many system factors that influence the safety of the process. To make progress in contributing to the reduction of medication errors, nursing schools must adopt a process improvement mindset and apply the findings to inform teaching strategies (Latimer et al., 2017). The findings should also be shared with clinical practice site partners to alert them to vulnerabilities in their medication management systems, thereby contributing to the creation of safer systems for our students/clinical instructors, for patients, and for all health care professionals. 


\section{Limitations}

The main limitation to this ongoing quality improvement project is the context. The project focused on a nursing program at one university, and only one year of data has been reported. Further testing of the definitions and categories of data is recommended to ensure accuracy, ease of reporting, and reliability. Adaptation of the framework by other nursing schools both nationally and internationally is recommended to advance this work.

\section{Conclusion}

Medication administration is a complex, high-risk activity that accounts for a significant amount of a nurse's workday. Medication errors continue to occur at alarming rates despite the implementation of safety technology and the introduction of a variety of safe practices. Nursing schools play a significant role in teaching the medication administration process and therefore play a significant role in error prevention. From our experience, this journey begins with the development of a culture of safety that encourages reporting; the next step is to use the data to inform the development of strategies to reduce and/or prevent these incidents.

A lack of reporting of medication incidents by nurses is a major barrier to understanding the system factors that contribute to errors and therefore our understanding of how to prevent them. This inaction continues to place patients in our care at risk. Our mission should be to prepare the current generation of nursing students with a strong commitment to report all incidents and provide them with the competencies and a reporting system that allows them to report efficiently and effectively. As they enter the workforce, they can begin to influence the reporting practices of seasoned nurses.

Our future plans include refining the language in the online reporting form and sharing our format with other schools of nursing to evaluate its usefulness. Our most recent data show a significant increase in reporting of near misses and discovered errors, a sign that our culture of safety is continuing to improve. 


\section{References}

Agency for Healthcare Research and Quality. (2019). Patient safety primer culture of safety. https://psnet.ahrq.gov/primers/primer/5

Asensi-Vicente, J., Jimenez-Ruiz, I., \& Vizcaya-Moreno, M. F. (2018). Medication errors involving nursing students: A systematic review. Nurse Educator, 43(5). E1-E5. https://doi.org/10.1097/NNE.0000000000000481

Baker, G. R., Norton, P. G., Flintoft, V., Blais, R., Brown, A., Cox, J., Etchells, E., Ghali, W. A., Hébert, P., Majumdar, S. R., O'Beirne, M., Palacios-Derflingher, L., Reid, R. J., Sheps, S., \& Tamblyn, R. (2004). The Canadian adverse events study: The incidence of adverse events among hospital patients in Canada. Canadian Medical Association Journal, 170(11), 1678-1686.

Bourbonnais, F., \& Caswell, W. (2014). Teaching successful medication administration today: More than just knowing your "rights." Nurse Education in Practice, 14, 391-395.

Brame, C. (2016). Active learning. Vanderbilt University Center for Teaching. https://cft.vanderbilt.edu/active-learning/

Carman, K., Dardess, P., Maurer, M., Sofaer, S., Adams, K., Bechtel, C., \& Sweeney, J. (2013). Patient and family engagement: A framework for understanding the elements and developing interventions and policies. Health Affairs, 32(2). https://doi.org/10.1377/hlthaff.2012.1133, 223-231

Cohen, M. (2007). Causes of medication errors. In M. Cohen (Ed.), Medication errors (pp. 5566). American Pharmacists Association.

College of Nurses of Ontario. (2019). Entry-to-practice competencies for registered nurses. https://www.cno.org/globalassets/docs/reg/41037_entrytopracitic_final.pdf

Cooper, E. (2014). Nursing student medication errors: A snapshot view from a school of nursing's quality and safety officer. Journal of Nursing Education, 53(3), S51-S54.

Covell, C., \& Ritchie, J. (2009). Nurses' responses to medication errors: Suggestions for the development of organizational strategies to improve reporting. Journal of Nursing Care Quality, 24(4), 287-297.

Cronenwett, L., Sherwood, G., Barnsteiner, J., Disch, J., Johnson, J., Mitchell, P., Sulliva, D., \& Warren, J. (2007). Quality and safety education for nurses. Nursing Outlook, 55(3), 122131.

Dolansky, M., Druschel, K., Helba, M., \& Courtney, K. (2013). Nursing student medication errors: A case study using root cause analysis. Journal of Professional Nursing, 29(2), 102-108.

Harding, L., \& Petrick, T. (2008). Nursing student medication errors: A retrospective review. Journal of Nursing Education, 47(1), 43-47.

Hess, L., Gaunt, M., \& Grissinger, M. (2016). Medication errors involving healthcare students. The Pennsylvania Patient Safety Authority, 13(1), 18-23.

Hewitt, P. (2010). Nurses' perceptions of the causes of medication errors: An integrative literature review. Medsurg Nursing, 19(3), 159-167. 
Incident Analysis Collaborating Parties. (2012). Canadian incident analysis framework. Canadian Patient Safety Institute.

Institute for Safe Medication Practices Canada. (2018). Students have a key role in a culture of safety: A multi-incident analysis of student-associated medication incidents. ISMP Canada Safety Bulletin, 18(2), 1-3.

Keers, R., Williams, S., Cooke, J., \& Ashcroft, D. (2013). Prevalence and nature of medication administration errors in health care settings: A systematic review of direct observational evidence. Pharmacoepidemiology, 47, 237-256.

Latimer, S., Hewitt, J., Stanbrough, R., \& McAndrew, R. (2017). Reducing medication errors: Teaching strategies that increase nursing students' awareness of medication errors and their prevention. Nurse Education Today, 52, 7-9.

Leape, L. L., Bates, D. W., Cullen, D. J., Cooper, J., Demonaco, H. J., Gallivan, T., Hallisey, R., Ives, J., Laird, N., Laffel, G., Nemeskal, R., Petersen, L. A., Porter, K., Servi, D., Shea, B. F., Small, S. D., Sweitzer, B. J., Thompson, B. T., \& Vander Vliet, M. (1995). Systems analysis of adverse drug events. Journal of the American Medical Association, 274(1), 35-43.

Ogrinc, G., Davies, L., Goodman, D., Batalden, P., Davidoff, F., \& Stevens, D. (2015). SQUIRE 2.0 (standards for quality improvement reporting excellence): Revised publication guidelines from a detailed consensus process. British Medical Journal Quality and Safety, 25(12). https://doi.org/10.1136/bmjqs-2015-004411

Reason, J. (1997). Engineering a safety culture. In Managing the risks of organizational accidents (pp. 191-222). Ashgate Publishing.

Reason, J. (2000). Human error: Models and management. British Medical Journal, 320, 768770.

RiskAnalytica. (2017). The case for investing in patient safety in Canada. http://www.patientsafetyinstitute.ca/en/toolsResources/case-for-investing-in-patientsafety/Pages/default.aspx

Rohde, E., \& Domm, E. (2018). Nurses' clinical reasoning practices that support safe medication administration: An integrative review of the literature. Journal of Clinical Nursing, 27, e402-e411.

Wolf, Z., Hicks, R., \& Serembus, J. (2006). Characteristics of medication errors made by nursing students during the administrative phase: A descriptive study. Journal of Professional Nursing, 22(1), 39-51. https://doi.org/101016/j.profnurs.2005.12.008

World Health Organization. (2017). Medication without harm: Global patient safety challenge on medication safety.

Zhu, J., Stuver, S., Epstein, A., Schneider, E., Weissman, J., \& Weingart, S. (2011). Can we rely on patients' reports of adverse events? Medical Care, 49(10), 948-955. 